\title{
Electrochemical Oxidation and Determination of Antiviral Drug Acyclovir by Modified Carbon Paste Electrode With Magnetic CdO Nanoparticles
}

\section{OPEN ACCESS}

Edited by:

Hassan Karimi-Maleh,

University of Electronic Science and

Technology of China, China

Reviewed by:

Alexandru Mihai Grumezescu,

Politehnica University of

Bucharest, Romania

Fatemeh Karimi,

Ton Duc Thang University, Vietnam

Somaye Cheraghi,

Shahid Bahonar University of

Kerman, Iran

Vahid Arabali,

Islamic Azad University Sari

Branch, Iran

*Correspondence:

Mehdi Rahimi-Nasrabadi rahiminasrabadi@gmail.com

Farhad Ahmadi

farhadlihnf@yahoo.com

Specialty section:

This article was submitted to

Analytical Chemistry,

a section of the journal

Frontiers in Chemistry

Received: 21 May 2020

Accepted: 02 July 2020

Published: 10 September 2020

Citation:

Naghian E, Marzi Khosrowshahi E.

Sohouli E, Pazoki-Toroudi HR,

Sobhani-Nasab A

Rahimi-Nasrabadi M and Ahmadi F

(2020) Electrochemical Oxidation and

Determination of Antiviral Drug

Acyclovir by Modified Carbon Paste

Electrode With Magnetic CdO

Nanoparticles. Front. Chem. 8:689.

doi: 10.3389/fchem.2020.00689

\author{
Ebrahim Naghian ${ }^{1,2,3}$, Elnaz Marzi Khosrowshahi ${ }^{4}$, Esmail Sohouli ${ }^{5}$, \\ Hamid Reza Pazoki-Toroudi ${ }^{6}$, Ali Sobhani-Nasab ${ }^{7,8}$, Mehdi Rahimi-Nasrabadi ${ }^{1,2 *}$ and \\ Farhad Ahmadi ${ }^{6,9 *}$
}

${ }^{1}$ Chemical Injuries Research Center, Systems Biology and Poisonings Institute, Baqiyatallah University of Medical Sciences, Tehran, Iran, ${ }^{2}$ Faculty of Pharmacy, Baqiyatallah University of Medical Sciences, Tehran, Iran, ${ }^{3}$ Department of Chemistry, South Tehran Branch Islamic Azad University, Tehran, Iran, ${ }^{4}$ Faculty of Pharmacy, Tabriz University of Medical Sciences, Tabriz, Iran, ${ }^{5}$ Young Researchers and Elites Club, Science and Research Branch, Islamic Azad University, Tehran, Iran, ${ }^{6}$ Physiology Research Center, Iran University of Medical Sciences, Tehran, Iran, ${ }^{7}$ Social Determinants of Health (SDH) Research Center, Kashan University of Medical Sciences, Kashan, Iran, ${ }^{8}$ Core Research Lab, Kashan University of Medical Sciences, Kashan, Iran, ${ }^{9}$ Department of Medicinal Chemistry, School of Pharmacy-International Campus, Iran University of Medical Sciences, Tehran, Iran

With the development of nanomaterials in electrochemical sensors, the use of nanostructures to modify the electrode surface has been shown to improve the kinetics of the electron transfer process. In this study, a sensor was developed for the electrochemical determination of Acyclovir (ACV) based on the modified carbon paste electrode (CPE) by $\mathrm{CdO} / \mathrm{Fe}_{3} \mathrm{O}_{4}$. The magnetic $\mathrm{CdO}$ nanoparticles characterization was studied by energy-dispersive X-ray spectroscopy (EDS) and X-ray diffraction (XRD). To study of the modified CPE surface morphology, scanning electron microscopy (SEM) was used. At the optimal conditions, a noteworthy enhancement in the electrochemical behavior of ACV was observed at the surface of the modified CPE compared to the unmodified CPE. A detection limit of $300 \mathrm{nM}$ and a linear range of $1-100 \mu \mathrm{M}$ were obtained for the quantitative monitoring of ACV at the modified CPE surface using differential pulse voltammetry (DPV) in phosphate buffer. The RSD\% (relative standard deviation) of the electrode response was $<4.3 \%$ indicating the development of a high precision method. Also, satisfactory results were obtained in the determination of ACV with the modified electrode in tablet, blood serum, and urine samples with a satisfactory relative recovery (RR\%) in the range of $94.0-104.4 \%$.

Keywords: acyclovir, antiviral drug, carbon paste electrode, electrochemical sensor, magnetic cadmium oxide, nanoparticle

\section{INTRODUCTION}

Herpes simplex is a type of skin infection caused by the herpes hominies virus (Braun-Falco et al., 1991) and is commonly known as herpes blister. There are two different types of herpes simplex virus types 1 and 2 of the herpes virus family that infect humans. The immune system removes the virus from the skin, but the virus hides itself in the nerves and may reappear in the future. 
2-amino-9-[(2-hydroxyethoxy) methyl]-6,9-dihydro-3H-purin6-one or acyclovir (ACV) is one of the effective drugs for reduces of this virus (Piret and Boivin, 2017). ACV is an antiviral drug with significant activity. It plays a significant role in the treatment of the virus illnesses and is very distinctive in helping the body to fight infection effectively and provide the necessary immunity. ACV does not completely cure herpes disease, but it certainly works to reduce the symptoms and spread herpes infection (Kłysik et al., 2020; Luyt et al., 2020). $\mathrm{ACV}$ is widely used in the therapy of herpes zoster infections, herpes simplex, herpetic encephalitis, primary genital herpes, and varicella-zoster virus infections in immunosuppressed patients. It is also helpful in inhibiting HSV infections in renal allograft receptors (Tenser and Tenser, 2019) and its anti-hepatitis B virus activity has been demonstrated (Huang et al., 2011). ACV may lead to neurotoxicity (coma, hallucinations, lethargy, tremors, and seizures) and nephrotoxicity (crystallization of ACV within renal tubules, transient, and enhancement of serum creatinine) (Fleischer and Johnson, 2010). As ACV is structurally similar to endogenous substances and because of its high solubility in water, it is very difficult to isolate and measure it in biological fluids. Therefore, its analysis in human serum is complicated and requires high selective analytical methods. With notice of these facts, the quantitative monitoring of ACV in biological fluids and other real samples appears very important. Several analytical methods have been developed for the analysis of $\mathrm{ACV}$ including near-infrared spectroscopy ( $\mathrm{Yu}$ and Xiang, 2008), fluorimetric and photometric methods (Macka et al., 1993), radioimmunoassay (RIA) (Tadepalli and Quinn, 1996), and LC (liquid chromatography) (Tzanavaras and Themelis, 2007; Mulabagal et al., 2020). The mentioned methods are commonly needed expensive equipment, more time and tedious processes. For example, LC methods need to optimize the chromatographic conditions and samples preparation or RIA method hands the radioactive wastes. Although, electrochemical methods including differential pulse voltammetry (DPV), cyclic voltammetry $(\mathrm{CV})$, square wave voltammetry, amperometry, electro-chemiluminescence, and polarography (Wang et al., 2006, 2013; Heli et al., 2010; Shetti et al., 2012, 2017; KarimNezhad et al., 2018) provide advantages such as simplicity, high sensitivity, low cost, fast response, and more environmentally friendly techniques (Adib et al., 2016; Rahimi-Nasrabadi et al., 2017; Amani et al., 2018a,b; Khoshroo et al., 2018, 2019; Naghian et al., 2020; Sanatkar et al., 2020; Sohouli et al., 2020a,b). Metal oxide nanoparticles have been extensively developed in the past decades. Among the metal oxide nanoparticles, cadmium oxide nanoparticles (CdONPs) are attractive because of wide non-toxicity, high isoelectric point and large surface area. So, CdNPs is a promising candidate for support material in the construction of the biosensors (Jing and Bowser, 2011; Fouladgar, 2018; Malekmohammadi et al., 2018; Kumar H.C. et al., 2019; Maduraiveeran et al., 2019; Mitra et al., 2019). metal nanoparticles modified electrodes show rapid redox activity toward the compounds with slow electron kinetics at bare electrodes, resolve overlapped peaks of analytes with close oxidation potentials and reveal good peak to peak separations (Baig et al., 2019; Sajid and Baig, 2019; Sinha et al., 2019). Metal ferrite or magnetic compounds have long been considered owing to its unique properties such as chemical and thermal stability, lower toxicity relative to other metals and cost-effectiveness. The most special and important property of metal ferrite for electrochemical applications is its good conductivity which originates from charge hopping of carriers between cations occupying the octahedral site (Beitollai et al., 2019; Khorshed et al., 2019; Kumar S. et al., 2019; Pastucha et al., 2019).

In this paper, a novel magnetic cadmium oxide $\mathrm{CdO} / \mathrm{Fe}_{3} \mathrm{O}_{4}$ modifier was used to modify a carbon paste electrode (CPE). The electrocatalytic activity of the modified CPE was investigated for the detection and analysis of ACV using DPV. The interaction between cadmium ion and ACV enhances the accumulation of the drug on the surface of the modified electrode and increasing the sensitivity of the measurement. After optimization of the experimental parameters, the modified electrode was used for analyses of the low level of ACV in real samples including biological fluid (plasma and urine) and tablet.

\section{EXPERIMENTAL}

\section{Instrumentation}

Voltammetric measurements were performed using a threeelectrode system consisting of the $\mathrm{Ag} / \mathrm{AgCl}$ electrode as the reference electrode (Azar Electrode Co., Iran), the platinum wire as the auxiliary electrode (Azar Electrode Co., Iran) and a modified $\mathrm{CPE}$ as the working electrode. A $\mu$-Autolab type III/FRA2 potentiostat/galvanostat with NOVA software was used for impedance measurements. To determine the structure and morphology of synthesized magnetic nanoparticles, FESEM images were obtained the SIGMA VP field emission scanning electron microscope coupled with EDS analysis and FEI NOVA NanoSEM450 instrument. X-ray diffraction (XRD) patterns were recorded by a Philips-X'pertpro, diffractometer containing Nifiltered $\mathrm{Cu} \mathrm{Ka}$ radiation. The Metrohm pH meter (Model 691) was used to adjust the solutions' $\mathrm{pH}$. The voltammograms were recorded via the PSTrace software and all data analysis were performed using Excel software.

\section{Chemicals and Reagents}

All chemicals were prepared in high purity analytical grade from Merck Company (Germany). ACV standard powder was obtained from the Rouz Darou Company. The Stock solutions of ACV were prepared by dissolving the appropriate amounts in a suitable volume of water before analysis. Other standard solutions were obtained by diluting the stock solutions with phosphate buffer solution.

\section{Synthesis of $\mathrm{Fe}_{3} \mathrm{O}_{4}$ Nanoparticles}

The $\mathrm{Fe}_{3} \mathrm{O}_{4}$ magnetic nanoparticles were synthesis by a reaction between $0.02 \mathrm{~mol}$ of iron (II) chloride and $0.03 \mathrm{~mol}$ of iron (III) chloride. These salts were dissolved in a $40 \mathrm{~mL}$ of degassed $\mathrm{HCl}$ $(0.4 \mathrm{M})$ solution and then $375 \mathrm{~mL}$ of degassed ammonia solution (25\%) was added to the above solution during $45 \mathrm{~min}$ drop by drop under sonication. After that, the black precipitate $\left(\mathrm{Fe}_{3} \mathrm{O}_{4}\right.$ nanoparticles) was formed. Finally, the separated products were 


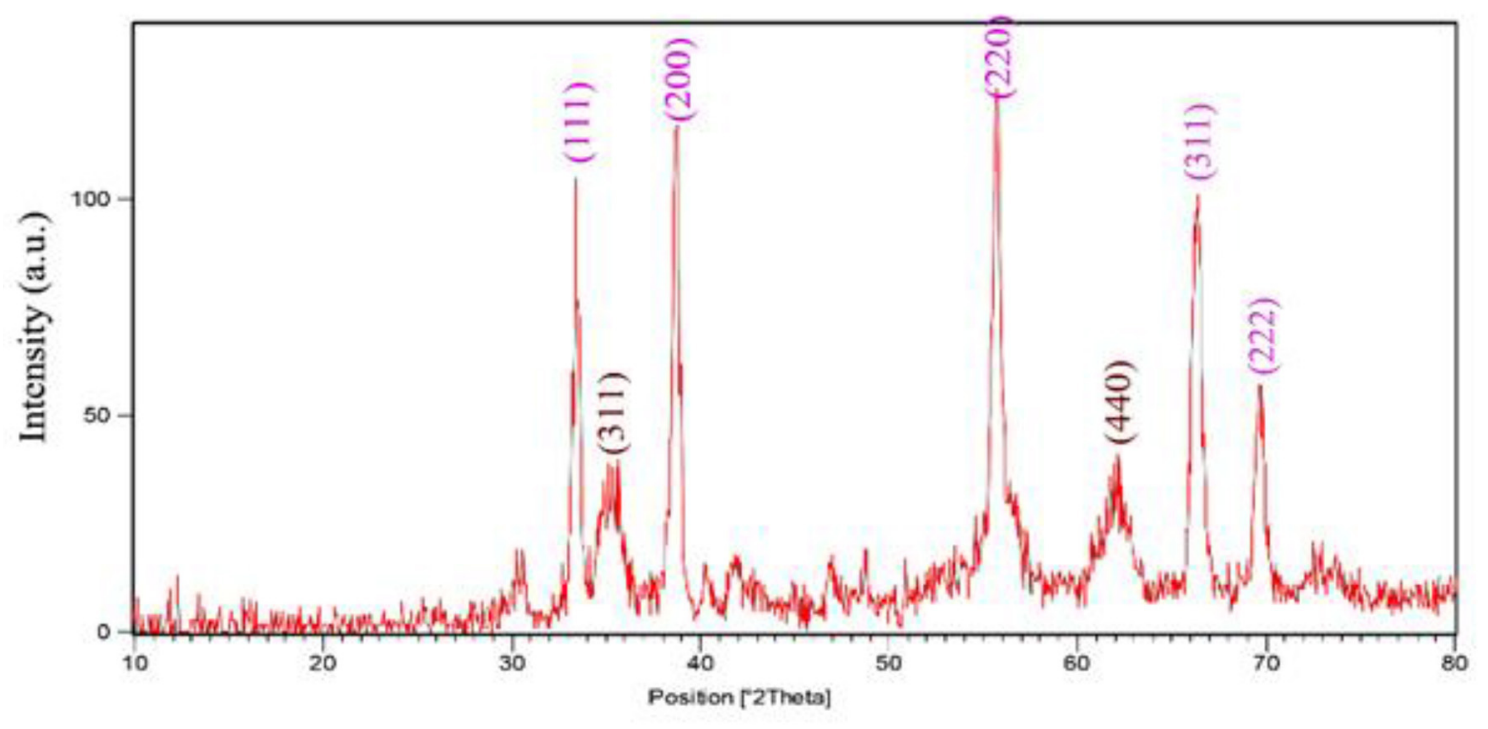

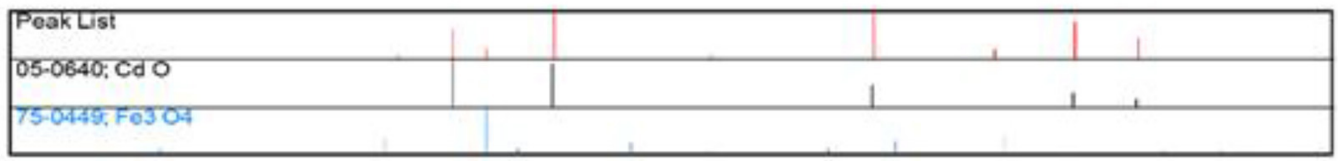

FIGURE 1 | The XRD pattern of $\mathrm{CdO} / \mathrm{Fe}_{3} \mathrm{O}_{4}$

washed with ethanol and deionized water and dried in an oven at $70^{\circ} \mathrm{C}$ (Enayat, 2018).

\section{Synthesis of $\mathrm{CdO} / \mathrm{Fe}_{3} \mathrm{O}_{4}$ Nanoparticles}

The synthesized $\mathrm{Fe}_{3} \mathrm{O}_{4}$ nanoparticles were dispersed in $50 \mathrm{~mL}$ of deionized water. The dispersion was stirred softly for $10 \mathrm{~min}$ to become homogenous. One millimole of cadmium nitrate warm solution $\left(70^{\circ} \mathrm{C}\right)$ and $\mathrm{Fe}_{3} \mathrm{O}_{4}$ dispersion were added to $50 \mathrm{~mL}$ of $\mathrm{NaOH}$ with a concentration of $2.5 \mathrm{~mol} \mathrm{~L}^{-1}$ under stirring conditions for $15 \mathrm{~min}$. Finally, the $\mathrm{CdO} / \mathrm{Fe}_{3} \mathrm{O}_{4}$ precipitation was rinsed with distilled water and after drying, it was calcined at $450^{\circ} \mathrm{C}$ for $70 \mathrm{~min}$ (Vosoughifar, 2018).

\section{Preparation of Modified Carbon Paste Electrode With Magnetic Nanoparticles}

$0.14 \mathrm{~g}$ of graphite, $0.01 \mathrm{~g}$ of magnetic nanoparticles and some oil were mixed to achieve a uniform paste. The resulting paste was then put into a plastic tube (id $=2 \mathrm{~mm}$ ). The electrical transmission was made using a copper wire. The surface of the electrode was polished on a paper sheet to be perfectly uniform. The unmodified $\mathrm{CPE}$ was obtained from a mixture of $0.15 \mathrm{~g}$ of graphite and oil with no modifier similar to the mentioned procedure.

\section{Tablet, Urine, and Plasma Samples Pretreatment}

To prepare tablet sample (ROUZ DAROU Co.), 10 tablets (each containing $200 \mathrm{mg}$ of ACV) were weighed and uniformly powdered. The $225 \mathrm{mg}$ of the obtained powder was dissolved in $100 \mathrm{~mL}$ of $0.1 \mathrm{M}$ phosphate buffer $(\mathrm{pH}=4)$. The resulting solution was diluted 500 -folds and stirred for $10 \mathrm{~min}$ to dissolve completely and finally it was filtered before use. Urine and plasma samples were stored in the refrigerator after collection. Then $5 \mathrm{ml}$ of the solutions were centrifuged for $5 \mathrm{~min}$ at 5,000 $\mathrm{rpm}$ (to remove suspended particles. These particles sometimes contaminate the surface by absorbing on the electrode and reduce its efficiency). The dilution with phosphate buffer $(\mathrm{pH}$ $=4$ ) was done at a ratio of 0.1 to reduce the matrix effect. The ACV content of samples was measured using the standard addition method.

\section{RESULTS AND DISCUSSION EDS and XRD Analysis of As-Synthesized Magnetic CdO}

The XRD patterns of $\mathrm{CdO} / \mathrm{Fe}_{3} \mathrm{O}_{4}$ nanostructures have been presented in Figure 1. As our results advice, $\mathrm{CdO} / \mathrm{Fe}_{3} \mathrm{O}_{4}$ nanostructure has high purity and two phases. The first phase is the $\mathrm{Fe}_{3} \mathrm{O}_{4}$ sample shows a series of diffraction peaks at the position of $35.45^{\circ}$ [(311) line], $43.08^{\circ}$ [(400) line], $57.16^{\circ}$ [(511) line], and $62.72^{\circ}[(440)$ line] that is in good agreement with the standard JCPDS file of $\mathrm{Fe}_{3} \mathrm{O}_{4}$ Cubic phase (space group Fd-3m, JCPDS No. 75-0449) and CdO shows a series of diffraction peaks at the position of $33.35^{\circ}$ [(111) line], $38.78^{\circ}$ [(200) line], $55.52^{\circ}$ [(220) line], $65.92^{\circ}$ [(311) line], and $69.33^{\circ}$ [(222) line] which is in good agreement with the standard JCPDS with the crystal structure of tetragonal (JCPDS 750592) with a space group of Fd-3m, respectively (Vosoughifar, 

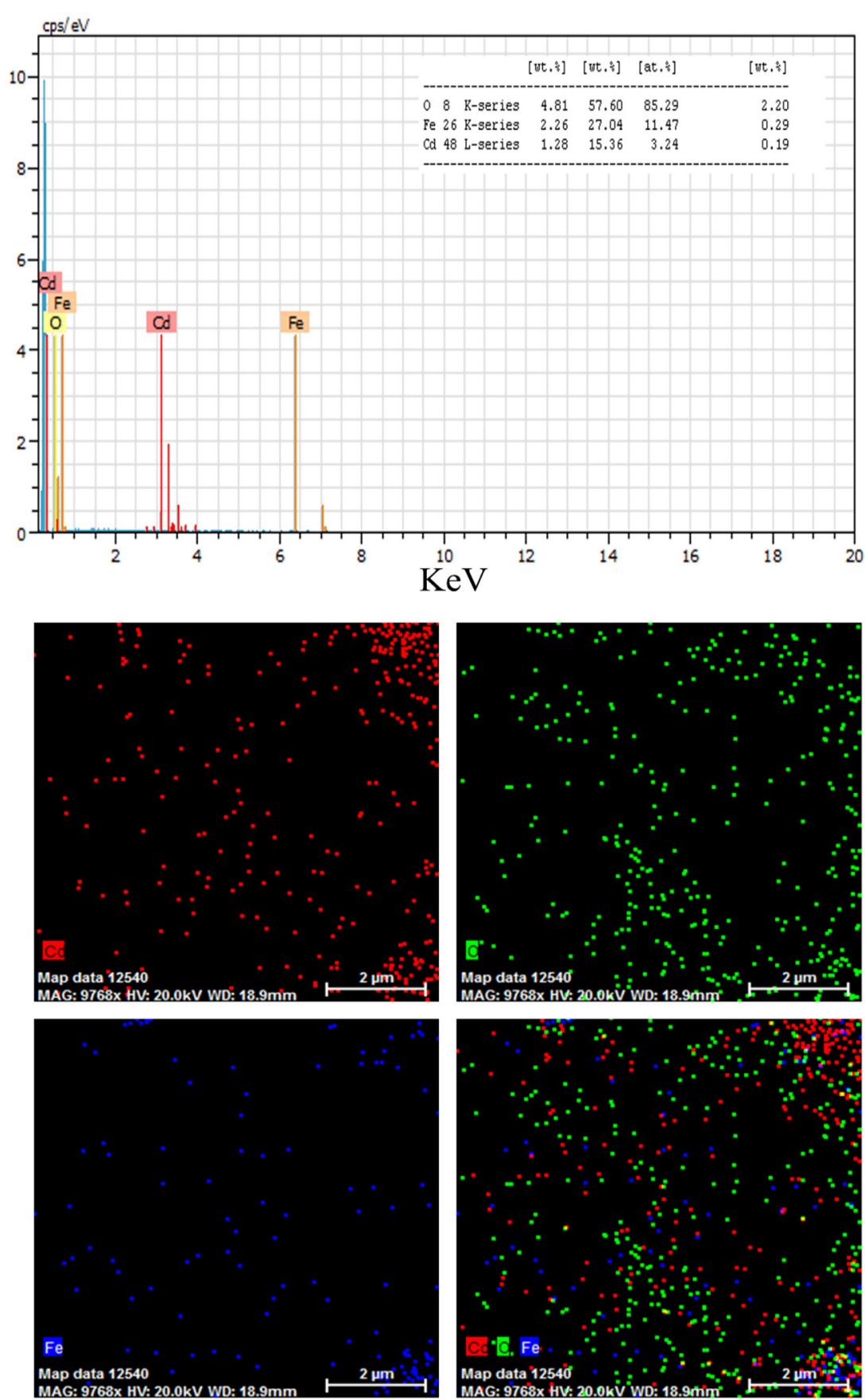

FIGURE 2 | The results of EDS analysis for $\mathrm{CdO} / \mathrm{Fe}_{3} \mathrm{O}_{4}$ nanoparticles.

2018). Crystalline sizes of nanoparticles are calculated from Scherer equation:

$$
\mathrm{Dc}=\mathrm{K} \lambda / \beta \operatorname{Cos} \theta
$$

where $\mathrm{K}$ is the shape factor, $\lambda$ is the $\mathrm{X}$-ray wavelength $(\mathrm{Cu} \mathrm{K} \alpha$ radiation, equals to $0.154 \mathrm{~nm}$ ), $\beta$ is the width of the observed diffraction peak at its half maximum intensity, which takes a value of about 0.9 and $\theta$ is the angle between the incident beam and the sample surface. The $\mathrm{CdO} / \mathrm{Fe}_{3} \mathrm{O}_{4}$ nanoparticles sizes were about $23 \mathrm{~nm}$. The EDS analysis approves the presence of $\mathrm{Cd}, \mathrm{Fe}$ and oxygen elements with no impurity (Figure 2).

\section{Optimization of the Percentage of Magnetic Nanoparticles}

To achieve the high-performance CPE, a suitable ratio between oil and graphite is needed (9-10\%). Higher and lower percentages 


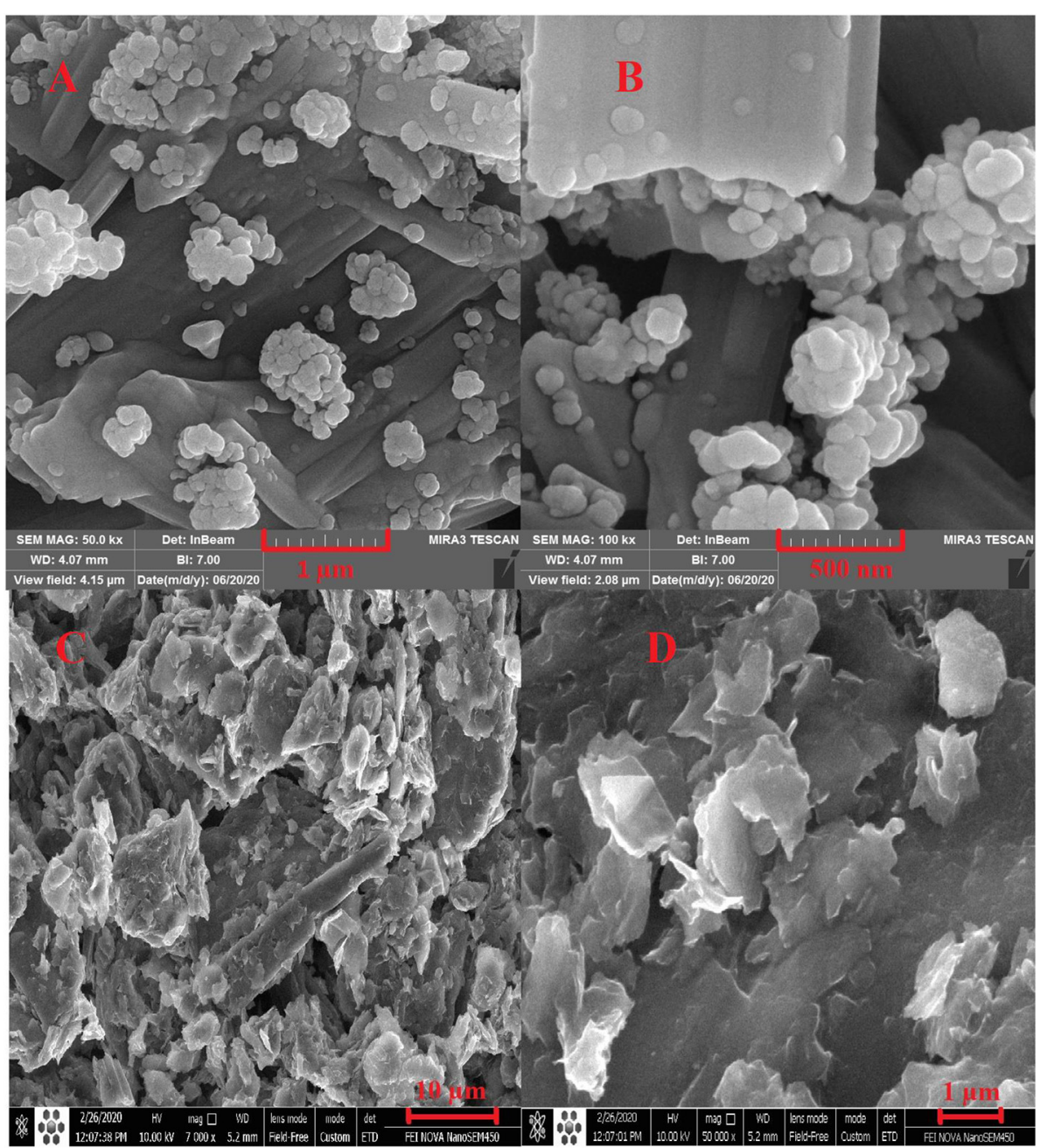

FIGURE 3 | The SEM images of magnetic CdO nanoparticles (A,B) and carbon paste with magnetic CdO (C,D).

are not suitable because the high amounts of oil obtain a flowing liquid and increase the surface hydrophobicity. In lower oil percentages, the electrode absorbs water and falls apart. However, the percentage of nanoparticles should be optimized due to the effect on sensor sensitivity and signal amplification. For this purpose, $\mathrm{CPE}$ with different weight ratios of magnetic $\mathrm{CdO}$ : graphite $(3,5,7$, and $10 \%)$ were prepared and its efficiency for measuring $30 \mu \mathrm{A}$ of ACV was evaluated. The results showed that from 3 to 10 incremental trends are observed in the signal, but after $7 \%$ this trend continues with a lower slope, so for optimal consumption of nanoparticles, this value was used as the optimal percentage in the structure of the electrode.

\section{Working Electrode Surface Area and Microscopic Imaging}

The SEM technique was used to illustrate the morphology of magnetic nanoparticles after being embedded in the carbon paste matrix. Figure 3 shows that the CPE plate morphology becomes cavernous by adding nanoparticles and the surface area increases significantly. The enhancement of magnetic nanoparticles provides a more porous structure for the CPE and increases the active surface area of the electrode in contact with the electrolyte and the electroactive species.

The effective surface area of the electrode $\left(A, \mathrm{~cm}^{2}\right)$ was calculated from obtained $\mathrm{CV}$ data of $5 \mathrm{mM} \mathrm{K}_{3}\left[\mathrm{Fe}(\mathrm{CN})_{6}\right]$ with a diffusion coefficient $\left(D, \mathrm{Cm}^{2} \mathrm{~s}^{-1}\right)$ of $7.5 \times 10^{-6}$. It was calculated from the Randles-Sevcik equation (Bard and Faulkner, 2001):

$$
I_{p a}=2.69 \times 10^{5} n^{3 / 2} A C_{0} D^{1 / 2} v^{1 / 2}
$$

where $n$ is the number of transferred electrons in the oxidation and reduction process of ferrocyanide, $C$ is the concentration of ferrocyanide $\left(5 \times 10^{-9} \mathrm{~mol} \mathrm{~cm}^{-3}\right)$ and $v$ is the scan rate. The value of $\mathrm{CdO} / \mathrm{Fe}_{3} \mathrm{O}_{4} / \mathrm{CPE}$ surface area $\left(0.31 \mathrm{~cm}^{2}\right)$ is greater than the unmodified CPE $(0.14$ $\mathrm{cm}^{2}$ ) which can be lead to exist of more electrochemical reaction sites. 


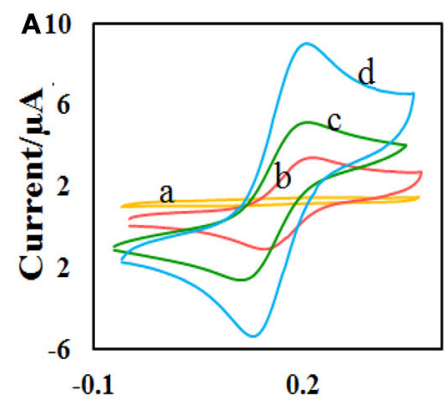

Potential/Vvs Ag / AgCl
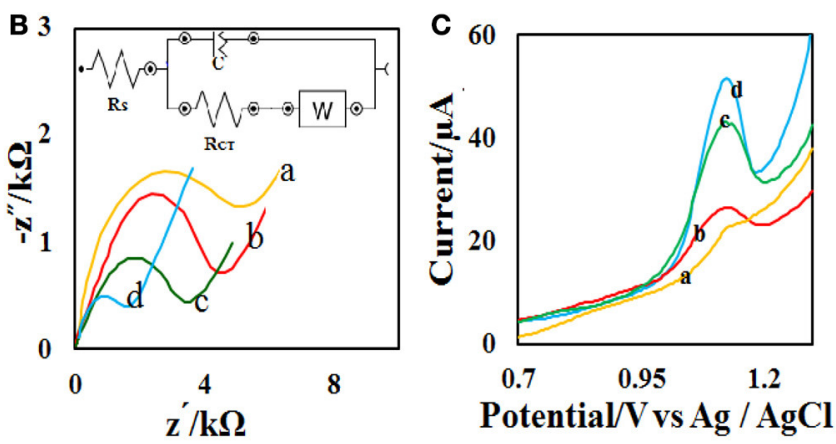

FIGURE 4 | (A) CVs and (B) Nyquist plots of the different modified electrodes in $0.1 \mathrm{M} \mathrm{PB}$ containing $5.0 \mathrm{mM}\left[\mathrm{Fe}(\mathrm{CN})_{6}\right]^{-3 /-4}$ at (a) bare, (b) CdO NP/CPE, (c) Fe ${ }_{3} \mathrm{O}_{4}$ $\mathrm{NP} / \mathrm{CPE}$, and (d) $\mathrm{CdO} / \mathrm{Fe}_{3} \mathrm{O}_{4} \mathrm{NP} / \mathrm{CPE}$ in the scan rate of $50 \mathrm{mV} \mathrm{s}^{-1}$ (C) The recorded DPVs of the (a) bare, (b) $\mathrm{CdO} \mathrm{NP} / \mathrm{CPE},(\mathrm{c}) \mathrm{Fe} \mathrm{O}_{3} \mathrm{NP} / \mathrm{CPE}$, and (d) $\mathrm{CdO} / \mathrm{Fe}_{3} \mathrm{O}_{4}$ $\mathrm{NP} / \mathrm{CPE}$ in presence of $50 \mu \mathrm{M}$ ACV.<smiles>Nc1nc2c([nH]c(=O)n2COCCO)c(=O)[nH]1</smiles>

FIGURE 5 | The ACV oxidation mechanism.
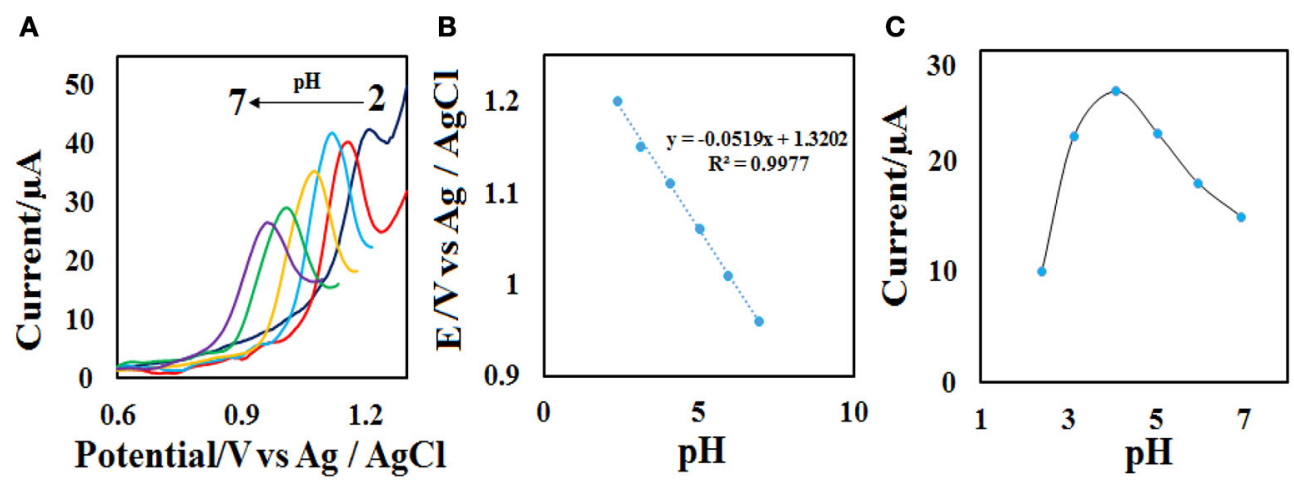

FIGURE 6 | (A) DPVs of the $\mathrm{CdO} / \mathrm{Fe}_{3} \mathrm{O}_{4} / \mathrm{CPE}$ at various $\mathrm{pH}$ values $\left(2,3,4,5,6\right.$, and 7). (B) Plots of the $E_{p}$ vs. $\mathrm{pH}$ value and (C) $I_{p}$ vs. pH value in the presence of $50 \mu \mathrm{M} \mathrm{ACV}$.

\section{Electro-Oxidation Behavior of the Redox Probe and ACV on the Modified CPE}

The CV technique was employed to evaluate the performance of the prepared electrodes. For this purpose, electrochemical measurements were done in the mixture of $\mathrm{Fe}^{2+} / \mathrm{Fe}^{3+}$ aqueous solution $(5 \mathrm{mM}$, molar ratio $1: 1)$ containing $0.1 \mathrm{M}$ potassium chloride in the potential range of -0.3 to $0.7 \mathrm{~V}$ (Figure 4A). At the CPE surface, the oxidation and reduction peaks of $\mathrm{Fe}^{2+} / \mathrm{Fe}^{3+}$ are very weak. However, when the electrode was modified with $\mathrm{CdO} / \mathrm{Fe}_{3} \mathrm{O}_{4}$ an oxidation-reduction peak for $\mathrm{Fe}^{2+} / \mathrm{Fe}^{3+}$ solution showed a difference between the peaks of $80 \mathrm{mV}$ indicating that this electrode has better capability rather than the unmodified electrode.

EIS (electrochemical impedance spectroscopy) was used to measure the surface resistance of different electrodes. The purpose of this section is to examine changes in the rate of electron transfer at different electrode surfaces. Figure 4B presents the Nyquist plots in the presence of $\mathrm{Fe}^{2+} / \mathrm{Fe}^{3+}$ aqueous solution $(5 \mathrm{mM})$ and $0.1 \mathrm{M}$ potassium chloride solution. Semicircular diameter indicates electron transfer resistance $\left(R_{\mathrm{ct}}\right)$ of the redox probe reaction. The $R_{\mathrm{ct}}$ parameter in this technique indicates the reaction kinetics at the electrode surfaces. The value of $R_{\mathrm{ct}}$ for CPE (5 k $\Omega$ ) bigger than the modified CPE $(1.2 \Omega)$. 


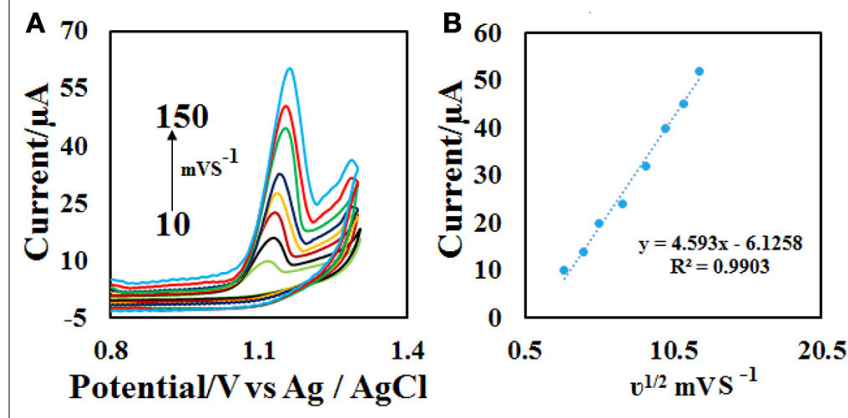

FIGURE 7 | (A) CVs on the $\mathrm{CdO} / \mathrm{Fe}_{3} \mathrm{O}_{4} / \mathrm{CPE}$ in $0.1 \mathrm{M}$ phosphate buffer $(\mathrm{pH}=$ 4.0) containing $50 \mu \mathrm{M} \mathrm{ACV}$ solution at different scan rates $\left(10-150 \mathrm{mVs}^{-1}\right.$ ) and $\mathbf{( B )}$ the plot of $(\mathbf{B}) I_{p}$ vs. $v^{1 / 2}$.
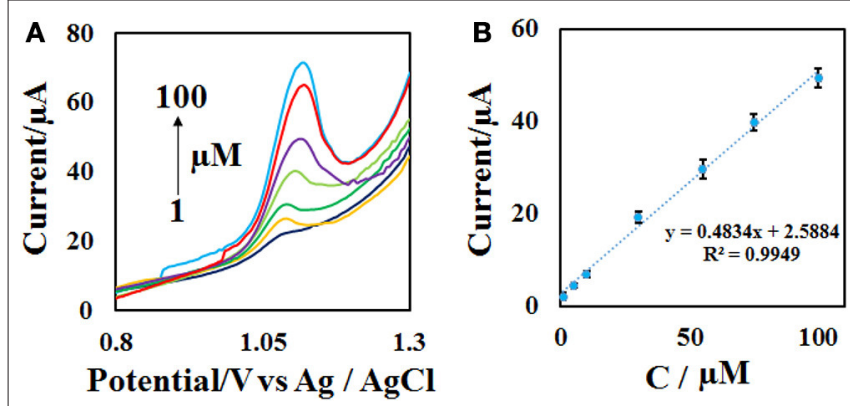

FIGURE 8 | (A) DPVs of the $\mathrm{CdO} / \mathrm{Fe}_{3} \mathrm{O}_{4} / \mathrm{CPE}$ in the presence of $1-100 \mu \mathrm{M}$ ACV in $0.1 \mathrm{M}$ phosphate buffer $(\mathrm{pH}=4)$ and the scan rate of $50 \mathrm{mV} \mathrm{s}^{-1}$ and (B) the calibration curve.

TABLE 1 | Comparison of the method with other electrochemical methods.

\begin{tabular}{|c|c|c|c|}
\hline Modifier/electrode & $\begin{array}{l}\text { Linear range } \\
\qquad(\mu \mathrm{M})\end{array}$ & $\operatorname{LOD}(\mu \mathrm{M})$ & References \\
\hline GCE/MWCNT/ZnO & $0.009-1$ & 0.006 & $\begin{array}{l}\text { Karim-Nezhad et al., } \\
2018\end{array}$ \\
\hline CPE/Nnao clay & $0.05-1$ & 0.0002 & Shetti et al., 2017 \\
\hline $\begin{array}{l}\text { GCE/MWCNT- } \\
\mathrm{DHP}^{\mathrm{a}}\end{array}$ & $0.79-130$ & 0.16 & Wang et al., 2006 \\
\hline GCE/C60 & $0.8-6$ & 0.15 & Shetti et al., 2012 \\
\hline CPE/PVPb & $0.01-75$ & 0.03 & Wang et al., 2013 \\
\hline CPE/CuNPs & $27-521$ & 2.6 & Heli et al., 2010 \\
\hline $\mathrm{CdO} / \mathrm{Fe}_{3} \mathrm{O}_{4} / \mathrm{CPE}$ & $1-100$ & 0.3 & This work \\
\hline
\end{tabular}

${ }^{a}$ Dihexadecyl hydrogen phosphate.

${ }^{b}$ Polyvinylpyrrolidone.

This behavior is due to the accelerate of the probe redox electron transfer at the $\mathrm{CdO} / \mathrm{Fe}_{3} \mathrm{O}_{4} / \mathrm{CPE}$ surface.

The electro-oxidation behavior of the analyte on the $\mathrm{CdO} / \mathrm{Fe}_{3} \mathrm{O}_{4} / \mathrm{CPE}$ surface was examined by the DPV method (Figure 4C). Comparison of the recorded DPVs of the bare, $\mathrm{CdO} / \mathrm{CPE}, \mathrm{Fe}_{3} \mathrm{O}_{4} / \mathrm{CPE}$, and $\mathrm{CdO} / \mathrm{Fe}_{3} \mathrm{O}_{4} / \mathrm{CPE}$ in presence of $50 \mu \mathrm{M} A C V$ shows that the oxidation of $\mathrm{ACV}$ on the $\mathrm{CdO} / \mathrm{Fe}_{3} \mathrm{O}_{4} / \mathrm{CPE}$ surface has a higher current and lower potential.

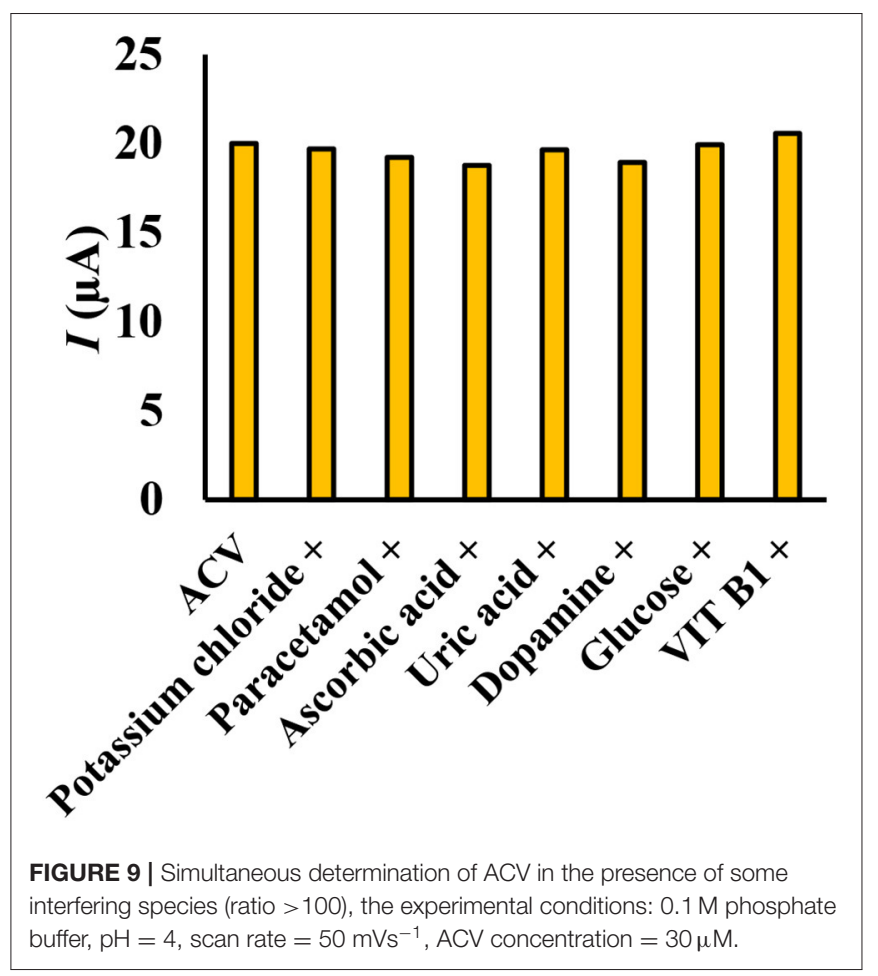

TABLE 2 | Determination of ACV content in real samples with relative recovery.

\begin{tabular}{lcccc}
\hline Sample & Added $(\boldsymbol{\mu} \mathbf{M})$ & Found $(\boldsymbol{\mu} \mathbf{M})$ & RR (\%) & $\begin{array}{c}\text { RSD } \\
\mathbf{( \% )}, \\
\boldsymbol{n}=\mathbf{5}\end{array}$ \\
\hline Tablet $(200 \mathrm{mg})$ & 0 & 20.2 & 100.1 & 2.3 \\
& 5 & 24.7 & 98.8 & 1.9 \\
& 10 & 30.2 & 100.6 & 1.9 \\
& 20 & 40.1 & 100.2 & 2.1 \\
\hline Urine & 0 & 0 & Not detected & - \\
& 10.0 & 9.4 & 94.0 & 1.9 \\
& 15.0 & 15.1 & 100.6 & 2.3 \\
& 30.0 & 31.1 & 103.4 & 1.7 \\
\hline \multirow{2}{*}{ Plasma } & 0 & 0 & Not detected & - \\
& 25.0 & 26.1 & 104.4 & 1.5 \\
& 35.0 & 34.4 & 98.3 & 2.1 \\
& 50.0 & 50.0 & 100.1 & 2.1 \\
\hline
\end{tabular}

\section{Effect of Electrolyte pH and Reaction Mechanism}

The effect of solution $\mathrm{pH}$ on the ACV oxidation peak in the $\mathrm{pH}$ ranges from 2 to 7 was investigated in the presence of phosphate buffer as a supporting electrolyte. The oxidation potential of ACV changed with increasing $\mathrm{pH}$. This indicates that the proton is involved in oxidative reactions. The oxidation potential of $\mathrm{ACV}$ is shifted to negative values by changing $\mathrm{pH}$. According to the structure of $\mathrm{ACV}$, the electrochemical oxidation process of ACV participates is equal protons and electrons (Figure 5). 
This mechanism is also confirmed by electrochemical methods presented in the previous work (Shetti et al., 2017). So the $\mathrm{pH}$ is important for the determination of $\mathrm{ACV}$ and its maximum oxidation current at developed sensor was obtained in $\mathrm{pH}=4$ that used for further studies (Figure 6).

\section{Effect of Scan Rate}

The effect of scan rate on the electrochemical properties of the $\mathrm{CdO} / \mathrm{Fe}_{3} \mathrm{O}_{4} / \mathrm{CPE}$ was investigated by the recording of the related voltammogram at different scan rates from 10.0 to $150.0 \mathrm{mV} \mathrm{s}^{-1}$ in the $0.1 \mathrm{M}$ phosphate buffer containing $50 \mu \mathrm{M}$ ACV. As seen in Figure $7 \mathbf{A}$, with the increase of scan rates the oxidation peak current increases and the $\mathrm{E}_{\mathrm{p}}$ value, slightly increases. The relationship between the oxidation peak currents $\left(I_{\mathrm{p}}\right)$ vs. the square root of the scan rate $\left(v^{1 / 2}\right)$ was obtained to be linear in the range of $10.0-150.0 \mathrm{mV} \mathrm{s}^{-1}$ under the corresponding equations including $I_{\mathrm{pa}}=4.593 v^{1 / 2}-6.1258$ (Figure 7B). These results emphasize a diffusion-controlled oxidation process at the $\mathrm{CdO} / \mathrm{Fe}_{3} \mathrm{O}_{4} / \mathrm{CPE}$ surface.

\section{Analytical Variation and Comparison of the Proposed Method With Other Electrosensors}

To achieve the working range of the developed sensor, the DPV of different concentrations of ACV (Figure 8A) were obtained at the optimal condition $(0.1 \mathrm{M}$ phosphate buffer with $\mathrm{pH}=4.0$ and the scan rate $\left.=50 \mathrm{mV} \mathrm{s}^{-1}\right)$ with 3 replicates. The plotting of current vs. concentration shows that the linear range of the method is in the range of $1-100 \mu \mathrm{M}$ with a detection limit of $0.3 \mu \mathrm{M}$ (Figure 8B). Other analytical performance parameters including repeatability and stability were investigated according to follow.

To investigate the repeatability of the modified electrode response, the ACV related voltammograms were plotted 5 times at three different concentrations and the RSD (relative standard deviation) of the electrode response was calculated. RSD values of the electrode response were $<4.3 \%$. The stability of the modified $\mathrm{CPE}$ was checked with the recording of ACV voltammograms once a week consecutively for 8 weeks. The results indicate that the desired $\mathrm{CdO} / \mathrm{Fe}_{3} \mathrm{O}_{4} / \mathrm{CPE}$ surface has long-term stability and in the eighth week, only a $5 \%$ signal decrease was observed compared with the first week.

In a comparison of the developed method with the other proposed methods for the measurement of ACV (Table 1) appears some advantages of this method. The used electrode is economical in comparing of glassy carbon electrode (GCE) or dispersed nanoparticles modifiers. Other analysis parameters such as the detection limit and the linear range are comparable and in some cases better than the presented methods.

\section{Interfering Effect}

To measure ACV in different matrices, it is necessary to investigate the effect of species that can oxidize or reduce on the electrode surface. The effect of different substances on the potential interaction of ACV determination at optimum conditions was studied. Interfering substances were selected from the group of substances present in biological and pharmaceutical fluids. The nuisance threshold was determined as the maximum species with an error of $<5 \%$ in the determination of ACV. The results (Figure 9) showed that the presence of glucose, ascorbic acid, dopamine, uric acid, paracetamol, acetaminophen, vitamin B1, and potassium chloride did not affect the sensor selectivity. It should be noted that these species do not have any overlapped peak in the same peak potential of ACV.

\section{Real Sample Analysis}

To investigate the application of the modified electrode in the electrochemical determination of ACV, tablet, urine and plasma samples were selected. Table 2 shows the results of this analysis. The results confirm the high performance of the modified electrode for measuring ACV in real samples. Each sample was spiked with three levels of ACV in the calibration range and the amount of ACV was obtained from the standard addition method. To achieve the relative recovery (RR) of the method, the ratio of ACV analytical signal in phosphate buffer and real samples was calculated. The recovery results (94.0-104.4\%) indicate good accuracy for the presented method in real samples.

\section{CONCLUSIONS}

The electrochemical behavior of ACV was investigated on an electrochemical sensor modified with magnetic $\mathrm{CdO}$ nanoparticles. The electrochemical response was a diffusion control process. High sensitivity and low detection limit $(300 \mathrm{nM})$, as well as easy preparation and easy surface recovery of the modified electrode, are the main advantages of this sensor. The proposed sensor as an effective electrochemical sensor was used to the ACV determination by DPV technique in biological fluids.

\section{DATA AVAILABILITY STATEMENT}

The raw data supporting the conclusions of this article will be made available by the authors, without undue reservation.

\section{ETHICS STATEMENT}

The studies involving human participants were reviewed and approved by ethics committee of Iran University of Medical Sciences. Written informed consent from the participants was not required to participate in this study in accordance with the national legislation and the institutional requirements.

\section{AUTHOR CONTRIBUTIONS}

All authors listed have made a substantial, direct and intellectual contribution to the work, and approved it for publication.

\section{ACKNOWLEDGMENTS}

The authors gratefully acknowledge the financial support of this work by Iran University of Medical Sciences with Grant No. 15507. Also, this proposal has the ethic code of IR.IUMS.REC.1398.665. 


\section{REFERENCES}

Adib, K., Rahimi-Nasrabadi, M., Rezvani, Z., Pourmortazavi, S. M., Ahmadi, F., Naderi, H. R., et al. (2016). Facile chemical synthesis of cobalt tungstates nanoparticles as high performance supercapacitor. J. Mater. Sci. Mater. Electron. 27, 4541-4550. doi: 10.1007/s10854-016-4329-4

Amani, J., Khoshroo, A., and Rahimi-Nasrabadi, M. (2018a). Electrochemical immunosensor for the breast cancer marker CA 15-3 based on the catalytic activity of a CuS/reduced graphene oxide nanocomposite towards the electrooxidation of catechol. Microchim. Acta 185, 79. doi: 10.1007/s00604-017-2532-5

Amani, J., Maleki, M., Khoshroo, A., Sobhani-Nasab, A., and RahimiNasrabadi, M. (2018b). An electrochemical immunosensor based on poly p-phenylenediamine and graphene nanocomposite for detection of neuronspecific enolase via electrochemically amplified detection. Analyt. Biochem. 548, 53-59. doi: 10.1016/j.ab.2018.02.024

Baig, N., Sajid, M., and Saleh, T. A. (2019). Recent trends in nanomaterial-modified electrodes for electroanalytical applications. TrAC Trends Analyt. Chem. 111, 47-61. doi: 10.1016/j.trac.2018.11.044

Bard, A. J., and Faulkner, L. R. (2001). Electrochemical Methods: Fundamentals and Applications, Vol. 2. New York, NY: John Wiley \& Sons, 482.

Beitollai, H., Mohammadi, S. Z., and Tajik, S. (2019). Electrochemical behavior of morphine at the surface of magnetic core shell manganese ferrite nanoparticles modified screen printed electrode and its determination in real samples. Int. J. Nano Dimens. 10, 304-312.

Braun-Falco, O., Plewig, G., Wolff, H. H., and Winkelmann, R. K. (eds.). (1991). "Erythematous and erythematosquamous skin diseases," in Dermatology (Berlin; Heidelberg: Springer), 403-466. doi: 10.1007/978-3-662-00181-3_14

Enayat, M. J. (2018). Fabrication of $\mathrm{Fe}_{3} \mathrm{O}_{4} / \mathrm{CaCO}_{3} / \mathrm{CuWO}_{4}$ heterostructures for enhanced photocatalytic activities for the degradation of organic dyes. J. Mater. Sci. Mater. Electron. 29, 19435-42. doi: 10.1007/s10854-018-0072-3

Fleischer, R., and Johnson, M. (2010). Acyclovir nephrotoxicity: a case report highlighting the importance of prevention, detection, and treatment of acyclovir-induced nephropathy. Case Rep. Med. 2010:602783. doi: 10.1155/2010/602783

Fouladgar, M. (2018). CuO-CNT nanocomposite/ionic liquid modified sensor as new breast anticancer approach for determination of doxorubicin and 5-fluorouracil drugs. J. Electrochem. Soc. 165:B559. doi: 10.1149/2. 1001811 jes

Heli, H., Zarghan, M., Jabbari, A., Parsaei, A., and Moosavi-Movahedi, A. (2010). Electrocatalytic oxidation of the antiviral drug acyclovir on a copper nanoparticles-modified carbon paste electrode. J. Solid State Electrochem. 14, 787-795. doi: 10.1007/s10008-009-0846-x

Huang, S.-T., Du, Y.-Z., Yuan, H., Zhang, X.-G., Miao, J., Cui, F.-D., et al. (2011). Synthesis and anti-hepatitis B virus activity of acyclovir conjugated stearic acid-g-chitosan oligosaccharide micelle. Carbohydrate Polym. 83, 1715-1722. doi: 10.1016/j.carbpol.2010.10.032

Jing, M., and Bowser, M. T. (2011). Methods for measuring aptamerprotein equilibria: a review. Analyt. Chim. Acta 686, 9-18. doi: 10.1016/j.aca.2010.10.032

Karim-Nezhad, G., Sarkary, A., Khorablou, Z., and Dorraji, P. S. (2018). Synergistic effect of $\mathrm{ZnO}$ nanoparticles and carbon nanotube and polymeric film on electrochemical oxidation of acyclovir. Iran J Pharm. Res. 17, 52-62.

Khorshed, A. A., Khairy, M., Elsafty, S. A., and Banks, C. E. (2019). Disposable screen-printed electrodes modified with uniform iron oxide nanocubes for the simple electrochemical determination of meclizine, an antihistamine drug. Analyt. Methods 11, 282-287. doi: 10.1039/C8AY02405G

Khoshroo, A., Hosseinzadeh, L., Sobhani-Nasab, A., Rahimi-Nasrabadi, M., and Ahmadi, F. (2019). Silver nanofibers/ionic liquid nanocomposite based electrochemical sensor for detection of clonazepam via electrochemically amplified detection. Microchem. J. 145, 1185-1190. doi: 10.1016/j.microc.2018.12.049

Khoshroo, A., Hosseinzadeh, L., Sobhani-Nasab, A., Rahimi-Nasrabadi, M., and Ehrlich, H. (2018). Development of electrochemical sensor for sensitive determination of oxazepam based on silver-platinum core-shell nanoparticles supported on graphene. J. Electroanalyt. Chem. 823, 61-66. doi: 10.1016/j.jelechem.2018.05.030
Kłysik, K., Pietraszek, A., Karewicz, A., and Nowakowska, M. (2020). Acyclovir in the treatment of herpes viruses-a review. Curr. Med. Chem. 25:4118-4137. doi: $10.2174 / 0929867325666180309105519$

Kumar, H. C., Shilpa, R., and Ananda, S. (2019). Synthesis of cadmium oxide nanoparticles by electrochemical method: its photodegradative effects on carboxylic acids and antibacterial behaviours. J. Nanosci. Technol. 5, 840-5. doi: $10.30799 /$ jnst.278.19050505

Kumar, S., Umar, M., Saifi, A., Kumar, S., Augustine, S., Srivastava, S., et al. (2019). Electrochemical paper based cancer biosensor using iron oxide nanoparticles decorated PEDOT: PSS. Analyt. Chim. Acta 1056, 135-45. doi: 10.1016/j.aca.2018.12.053

Luyt, C.-E., Forel, J.-M., Hajage, D., Jaber, S., Cayot-Constantin, S., Rimmelé, T., et al. (2020). Acyclovir for mechanically ventilated patients with herpes simplex virus oropharyngeal reactivation: a randomized clinical trial. JAMA Int. Med. 180, 263-272. doi: 10.1001/jamainternmed.2019.5713

Macka, M., Borak, J., Semenkova, L., Popl, M., and Mikeš, V. (1993). Determination of acyclovir in blood serum and plasma by micellar liquid chromatography with fluorimetric detection. J. Liquid Chromatogr. Related Technol. 16, 2359-2386. doi: 10.1080/10826079308020992

Maduraiveeran, G., Sasidharan, M., and Jin, W. (2019). Earth-abundant transition metal and metal oxide nanomaterials: synthesis and electrochemical applications. Progr. Mater. Sci. 106:100574. doi: 10.1016/j.pmatsci.2019.100574

Malekmohammadi, S., Hadadzadeh, H., Farrokhpour, H., and Amirghofran, Z. (2018). Immobilization of gold nanoparticles on folate-conjugated dendritic mesoporous silica-coated reduced graphene oxide nanosheets: a new nanoplatform for curcumin $\mathrm{pH}$-controlled and targeted delivery. Soft Matter 14, 2400-2410. doi: 10.1039/C7SM02248D

Mitra, S., Purkait, T., Pramanik, K., Maiti, T. K., and Dey, R. S. (2019). Threedimensional graphene for electrochemical detection of Cadmium in Klebsiella michiganensis to study the influence of Cadmium uptake in rice plant. Mater. Sci. Eng. C 103:109802. doi: 10.1016/j.msec.2019.109802

Mulabagal, V., Annaji, M., Kurapati, S., Dash, R. P., Srinivas, N. R., Tiwari, A. K., et al. (2020). Stability-indicating HPLC method for acyclovir and lidocaine in topical formulations. Biomed. Chromatogr. 34:e4751. doi: 10.1002/bmc.4751

Naghian, E., Khosrowshahi, E. M., Sohouli, E., Ahmadi, F., Rahimi-Nasrabadi, M., and Safarifard, V. (2020). A new electrochemical sensor for the detection of fentanyl lethal drug by a screen-printed carbon electrode modified with the open-ended channels of Zn (ii)-MOF. N. J. Chem. 44, 9271-9277. doi: 10.1039/D0NJ01322F

Pastucha, M., Farka, Z., Lacina, K., Mikušová, Z., and Skládal, P. (2019). Magnetic nanoparticles for smart electrochemical immunoassays: a review on recent developments. Microchim. Acta 186:312. doi: 10.1007/s00604-0193410-0

Piret, J., and Boivin, G. (2017). "Herpesvirus resistance to antiviral drugs," in Antimicrobial Drug Resistance, ed D. Mayers, J. Sobel, M. Ouellette, K. Kaye, and D. Marchaim (Cham: Springer), 1185-1211. doi: 10.1007/978-3-319-47266-9_24

Rahimi-Nasrabadi, M., Pourmohamadian, V., Karimi, M. S., Naderi, H. R., Karimi, M. A., Didehban, K., et al. (2017). Assessment of supercapacitive performance of europium tungstate nanoparticles prepared via hydrothermal method. $J$. Mater. Sci. Mater. Electron. 28, 12391-12398. doi: 10.1007/s10854-017-7059-3

Sajid, M., and Baig, N. (2019). Chemically modified electrodes for electrochemical detection of dopamine: challenges and opportunities. TrAC Trends Analyt. Chem. 118, 368-385. doi: 10.1016/j.trac.2019.05.042

Sanatkar, T. H., Khorshidi, A., Sohouli, E., and Janczak, J. (2020). Synthesis, crystal structure, and characterization of two $\mathrm{Cu}$ (II) and $\mathrm{Ni}$ (II) complexes of a tetradentate $\mathrm{N}_{2} \mathrm{O}_{2}$ Schiff base ligand and their application in fabrication of a hydrazine electrochemical sensor. Inorg. Chim. Acta 506:119537. doi: $10.1016 /$ j.ica.2020.119537

Shetti, N. P., Malode, S. J., and Nandibewoor, S. T. (2012). Electrochemical behavior of an antiviral drug acyclovir at fullerene-C60-modified glassy carbon electrode. Bioelectrochemistry 88, 76-83. doi: 10.1016/j.bioelechem.2012.06.004

Shetti, N. P., Nayak, D. S., Malode, S. J., and Kulkarni R. M. (2017). Nano molar detection of acyclovir, an antiviral drug at nanoclay modified carbon paste electrode. Sens. Bio Sens. Res. 14, 39-46. doi: 10.1016/j.sbsr.2017.04.004

Sinha, A., Chen, J., and Jain, R. (2019). "Functionalized graphenemetal nanoparticles nanohybrids as electrochemical sensors," in Graphene 
Functionalization Strategies, eds A. Khan, M. Jawaid, B. Neppolian, and A. Asiri (Singapore: Springer), 49-62. doi: 10.1007/978-981-32-9057-0_2

Sohouli, E., Keihan, A. H., Shahdost-fard, F., Naghian, E., Plonska-Brzezinska, M. E., Rahimi-Nasrabadi, M. et al. (2020a). A glassy carbon electrode modified with carbon nanoonions for electrochemical determination of fentanyl. Mater. Sci. Eng. C 110:110684. doi: 10.1016/j.msec.2020.110684

Sohouli, E., Shahdost-Fard, F., Rahimi-Nasrabadi, M., Plonska-Brzezinska, M. E., and Ahmadi, F. (2020b). Introducing a novel nanocomposite consisting of nitrogen-doped carbon nano-onions and gold nanoparticles for the electrochemical sensor to measure acetaminophen. J. Electr. Chem. 871:114309. doi: 10.1016/j.jelechem.2020.114309

Tadepalli, S. M., and Quinn, R. P. (1996). Scintillation proximity radioimmunoassay for the measurement of acyclovir. J. Pharmac. Biomed. Anal. 15, 157-163. doi: 10.1016/0731-7085(96)01835-3

Tenser, R. B., and Tenser, R. B. (2019). Acyclovir resistant HSV in immunocompromised patients. Neurology.

Tzanavaras, P. D., and Themelis, D. G. (2007). High-throughput HPLC assay of acyclovir and its major impurity guanine using a monolithic column and a flow gradient approach. J. Pharm. Biomed. Anal. 43, 1526-1530. doi: 10.1016/j.jpba.2006.11.002

Vosoughifar, A. (2018). Synthesis of $\mathrm{NiWO}_{4}$ nanostructure and $\mathrm{NiWO}_{4} / \mathrm{CdO}$ nanocomposites as an effective photocatalyst for enhanced degradation and removal of organic contaminant. J. Mater. Sci. 29, 4862-4868. doi: $10.1007 /$ s10854-017-8442-9
Wang, F., Chen, L., Chen, X., and Hu, S. (2006). Studies on electrochemical behaviors of acyclovir and its voltammetric determination with nano-structured film electrode. Anal. Chim. Acta 576, 17-22. doi: 10.1016/j.aca.2005.12.023

Wang, P., Gan, T., Zhang, J., Luo, J., and Zhang, S. (2013). Polyvinylpyrrolidone-enhanced electrochemical oxidation and detection of acyclovir. J. Mol. Liquids 177, 129-132. doi: 10.1016/j.molliq.2012. 11.009

Yu, L., and Xiang, B. (2008). Quantitative determination of acyclovir in plasma by near infrared spectroscopy. Microchem. J. 90, 63-66. doi: 10.1016/j.microc.2008.03.006

Conflict of Interest: The authors declare that the research was conducted in the absence of any commercial or financial relationships that could be construed as a potential conflict of interest.

Copyright (c) 2020 Naghian, Marzi Khosrowshahi, Sohouli, Pazoki-Toroudi, Sobhani-Nasab, Rahimi-Nasrabadi and Ahmadi. This is an open-access article distributed under the terms of the Creative Commons Attribution License (CC BY). The use, distribution or reproduction in other forums is permitted, provided the original author(s) and the copyright owner(s) are credited and that the original publication in this journal is cited, in accordance with accepted academic practice. No use, distribution or reproduction is permitted which does not comply with these terms. 